\title{
Influence of Water Flotation Technique on Seed and Seedling Quality Characteristics of Sesamum indicum.
}

\author{
N. Suma, P. Srimathi. \\ Department of Seed Science and Technology, Tamilnadu Agricultural University, Coimbatore-6
}

\begin{abstract}
The present Studies made with gingelly to upgrade the quality of seeds based on that specific gravity using water floatation technique seeds revealed that specific gravity grading using water improved the seed quality of gingelly with respect to seed recovery and seed quality characters.
\end{abstract}

Keywords: size grading,flotation, sesame, oilseed

\section{Introduction}

Sesame seed is an important source of edible oil. It is often considered as the "queen" of vegetable oils. More than 80 per cent of the crop is cultivated in kharif and a small quantity is cultivated in rabi . Therefore, sesame seed is available throughout the year in the country.

Homoginising the heterogeneous seed lot is the prime aim of any post harvest seed management techniques. The homogenisation is mainly based on physical characters, as it could be easily adoptable. Sesamum is a crop expressing all possible variation in physical character such as weight, colour and size necessitating the need for processing the seeds before sowing.

\section{Materials and Methods}

Genetically pure seeds of sesamum (Sesamum indium.) cv. CO1 obtained from Department of oilseeds, TNAU, Coimbatore, formed the base material for the study. The field experiments and laboratory experiments were conducted at Department of Seed Science and Technology, Tamil Nadu Agricultural University, Coimbatore $\left(11^{\circ} \mathrm{N}\right.$ latitude and $77^{\circ} \mathrm{E}$ longitude with an altitude of $427 \mathrm{~m}$ above mean sea level) during 2004-2005.

\section{Specific gravity grading based on water floatation.}

Bulk seeds were subjected to floatation grading by dropping $100 \mathrm{~g}$ of the seeds in four replication in a $500 \mathrm{ml}$ of water and stirred well and were allowed to stand for one to two minutes. The seeds were separated as sinkers and floaters (seeds that float in the column of water) collected separately and dried under shade for 2 days. After 2 days seed recovery was observed both for sinkers and floaters on weight basis and the seed and seedling quality characters were observed as detailed below.

Seed Recovery $(\%)$

Sinkers $(\%)=\quad \frac{\text { Weight of sinkers }}{\text { Total weight of seed }} \times 100$

Floaters $(\%)=\frac{\text { Weight of floaters }}{\text { Total weight of seed }} \times 100$

\section{0 seed weight (mg)}

Eight replicates of hundred seeds were drawn from each treatment, weighed in sensitive electronic balance and expressed in milligrams (ISTA, 1999).

\section{Germination (\%)}

Four replicates of hundred seeds were sown in sand medium and kept under the test conditions of $25^{\circ} \pm$ $1^{\circ} \mathrm{C}$ and $95^{\circ} \pm 3$ per cent relative humidity maintained in a germination room illuminated with fluorescent light. After the test period of seven days the normal seedlings were counted and the mean values expressed as percentage (ISTA, 1999) to the total number of seeds placed for germination.

\section{Root length (cm)}

At the time of germination count, ten normal seedlings were taken at random. The length between the collar and tip of the primary root was measured as root length and the mean length expressed in centimeter. 
Shoot length (cm)

From the ten seedlings used for measuring the root length, the length between collar and tip of the primary shoot was measured as shoot length and the mean value expressed in centimeter.

\section{Drymatter production ( $\mathrm{mg} 10$ seedlings ${ }^{-1}$ )}

Ten normal seedlings from the germination test were selected at random, dried in a hot air oven maintained at $85^{\circ} \mathrm{C}$ for $48 \mathrm{~h}$ and cooled in a desiccators for 30 minutes, and weighed in an electronic digital balance. The mean weight was expressed as dry matter production 10 seedlings $^{-1}$ in milligram (Gupta, 1993).

\section{Vigour index}

The Vigour index values were computed, adopting the procedure of Abdul-Baki and Anderson (1973) as given below and expressed as whole number.

Vigour index $=$ Germination $(\%)$ x Total seedling length $(\mathrm{cm})$

\section{Water floatation grading.}

\section{Results and Discussion}

Highly significant results were obtained due to water floatation grading for the evaluated seed and seedling quality characters (Table 1).

\section{Specific gravity grading based on water floatation}

Seeds are graded based on size as a component under post harvest seed handling technique, but researchers on sunflower (Balamurugan, 1993), moringa Sivasubramanian, 1996), cotton (Jayashree, 1996) and bhendi (Vijayakumar, 1996) opined that grading seeds based on their weight is better than size grading due to the genetic accommodation of embryo inside the seed coat. Gingelly in one such crop where more seed float due seed immaturity as the crop is harvested as once over harvest and because of its continuous flowering habit Hence an attempt was made with gingelly to upgrade the quality of seeds based on that specific gravity using water floatation technique.

In the present study the recovery of sinker seed was higher (94 per cent) than floater seed (6 per cent).(Fig 1) The floater seed recorded 49 per cent lesser seed weight than sinker seed.The heavier sinker seed recorded the maximum germination of 84 per cent, while, lighter floater recorded lesser germination than sinkers by 64 per cent and by 60 per cent compared to bulk. Anon (1996) in sorghum, sunflower and soybean and Patil and Sarode (1998) in wheat obtained similar effective association between seed weight and seed germination.

The seedling quality attributes evaluated through root and shoot measurement, drymatter production and vigour index values were in close association with the results of 100 seed weight and germination highlighting the efficacy of specific gravity grading for upgrading the seed quality characteristics of gingelly cv.CO1. Saraswathi (1995) in cotton observed similar association between specific gravity fractions and seedling vigour characteristics. Thus the study highlighted that specific gravity grading using water improved the seed quality of gingelly with respect to seed recovery and seed quality characters.

\section{References}

[1]. Agrawal, R.L. 1995. Seed Technology, Oxford and IBH. Publishing Co. PVT. Ltd., New Delhi.

[2]. Abbul - Baki, A.A. and J.D. Anderson,. 1973 Vigour determination in soybean seed by multiple criteria. Crop Sci., 13: 630-633

[3]. Balamuragan .P.,P.Srimathi and Sundaralingam . 2004. Influence of seed size on vigor and productivity of safflower. Dept of seed science and technology, Tamilnadu Agricultural University, Coimbatore.

[4]. Balamurugan, V. 2002. Nutrient management for seed yield maximization in rainfed sesame (Sesamum indicum L.) cv. CO 1. M.Sc. (Ag.) Thesis, Tamil Nadu Agricultural University, Coimbatore.

[5]. ISTA. 1999, International Rules for Seed testing. Seed Sci. \& Technol. (Supplement Rules) 27: 25-30.

[6]. Nachimuthu, A. 1997. Studies on the influence pelleting and foliar nutrient on plant growth yield and quality of seeds of Gingelly (Sesamum indicum L.) cv. TMV3, M.Sc. (Ag.) Thesis, Tamil Nadu Agricultural University, Coimbatore

[7]. Paul, S.R., N.N. Sharma and D. Sharma. 1997. Effect of seed size on germination and seedling vigour of mustard. Seed Tech., News., 27(3): 6

[8]. Rajasekaran, R. 2001. Seed production, processing and storage studies in niger (Guizotia abyrrinica L. f. cass.) cv. Paiyur 1, M.Sc. (Ag.) Thesis, Tamil Nadu Agricultural University, Coimbatore

[9]. Sabir Ahamed, A. 1989. Studies on the production of quality seed and storage in soyabean Glycine max (L.) Merrill. M.Sc. Thesis, Tamil Nadu Agricultural University, Coimbatore.

[10]. Saeed, EL.E.A.K 1966. Effect of seed size on oil content and seedling emergence in safflower. (Carthamus tinetorius) grown in sudan. Exp. Agric., 2(4): 299-304.

[11]. Setia, R.K. and Singh, J.N. 1973. Note on storage ability and vigour influenced by due the different grades of soybean seeds. Indian J. Agric. Res., 7(3-4) : 183-185.

[12]. Tewari, M.N. and P.C. Gupta, 1981. Effect of genotype, seed grade and environment on viability and vigour on sunflower seed in storage. Seed Res.,. 9(2): 126-131. 
Table1. Influence of water flotation technique on seed and seedling quality characteristics

\begin{tabular}{|c|c|c|c|c|c|c|c|}
\hline $\begin{array}{l}\text { Water } \\
\text { floatation } \\
\text { grading }\end{array}$ & $\begin{array}{l}\text { Seed } \\
\text { recovery } \\
(\%)\end{array}$ & $\begin{array}{l}100 \quad \text { seed } \\
\text { weight }(\mathrm{mg})\end{array}$ & $\begin{array}{l}\text { Germination } \\
(\%)\end{array}$ & $\begin{array}{l}\text { Root length } \\
\text { (cm) }\end{array}$ & $\begin{array}{l}\text { Shoot } \\
\text { length }(\mathrm{cm})\end{array}$ & $\begin{array}{l}\text { Dry matter } \\
\text { production 10 } \\
\text { seedling }^{-1}\left(\mathrm{mg}^{2}\right)\end{array}$ & Vigour index \\
\hline Sinkers & 94.0 & 334 & $(66.42)$ & 9.5 & 7.1 & 39.1 & 1394 \\
\hline Floaters & 6.0 & 171 & (26.57) & 6.0 & 4.5 & 25.0 & 210 \\
\hline Bulk & 0 & 306 & $(63.43)$ & 7.6 & 5.9 & 38.0 & 1080 \\
\hline $\mathrm{CD}(\mathrm{P}=0.05)$ & 0.299 & 1.948 & 1.152 & 0.310 & 0.387 & 0.662 & 1.037 \\
\hline
\end{tabular}

(Figures in parentheses are arc sine transformed values)

Fig.1.Influence of water flotation technique on seed germination,seed recovery and vigour index.

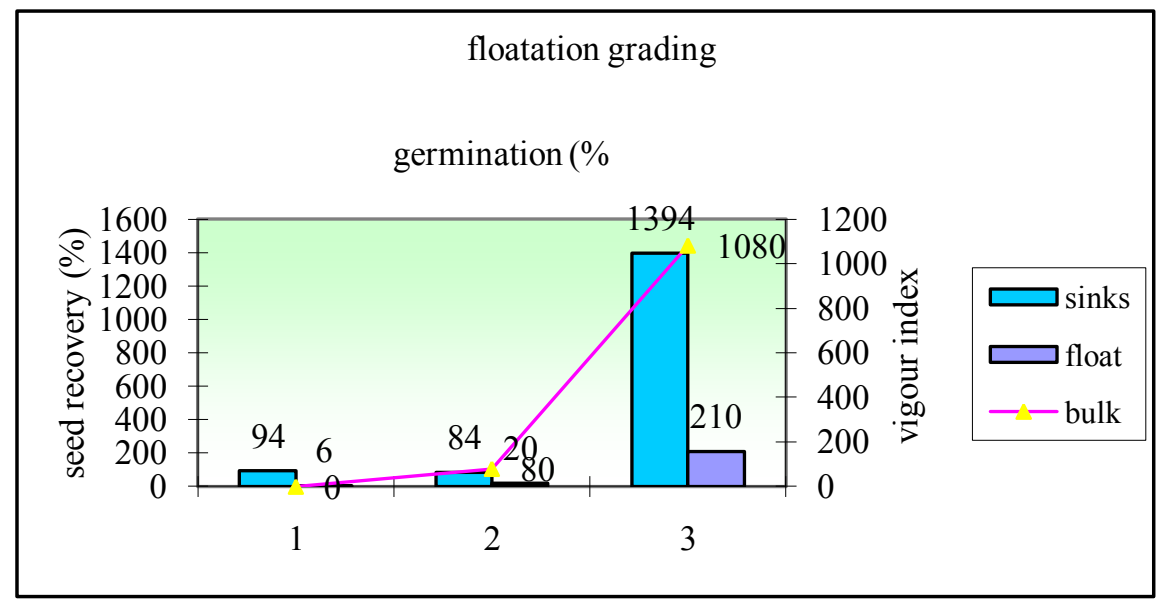

